\title{
Successive cases of an entrapped arterial catheter guidewire in separate patients on the same day
}

\author{
Larry Garcia, MD $\cdot$ John Davis, BSN • \\ Tracy Davis, AT $\cdot$ Noreen Durrani, MD • \\ Mark Welliver, DNP
}

Received: 24 August 2010/ Accepted: 7 September 2010/Published online: 12 November 2010

(C) Canadian Anesthesiologists' Society 2010

\section{To the Editor,}

We share our recent experiences with the Arrow ${ }^{\circledR}$ International radial artery catheterization set (Ref RA04020, Reading, PA, USA). After general anesthesia was induced and our patient's left radial artery was positioned and prepared, we introduced the Arrow catheter set into the site. Bright red blood was observed in the back flow tube that houses the guidewire. The guidewire was then advanced approximately $1 \mathrm{~cm}$ before gentle resistance was felt. Attempts at withdrawing the guidewire back into the catheter set were also met with resistance. Several additional attempts were made at withdrawal using slight traction and twisting on the guidewire, but without success. The Teflon ${ }^{\circledR}$ outer catheter, guidewire, and introducer needle were then withdrawn together as a unit; however, the guidewire uncoiled, remained secure within the tissues, and could not be removed despite attempts to pull it out. An immediate intraoperative $x$-ray (Figure) was performed, which showed the intact uncoiled guidewire kinked within the tissues. A vascular surgical consult was requested, and after consultation, a surgical cut-down was performed to

L. Garcia, MD $(\varangle) \cdot$ J. Davis, BSN · T. Davis, AT .

N. Durrani, MD - M. Welliver, DNP

University of Florida at Shands, Jacksonville, FL, USA

e-mail: lorenzo.garcia@jax.ufl.edu

J. Davis, BSN

School of Nursing, Nurse Anesthetist Program,

University of North Florida, Jacksonville, FL, USA

M. Welliver, DNP

Harris College of Nursing and Health Sciences,

School of Nurse Anesthesia, Texas Christian University,

Fort Worth, TX, USA

e-mail: mark.welliver@gmail.com retrieve the guidewire that was imbedded $1 \mathrm{~cm}$ within the subcutaneous tissues, but not within the artery. The site was closed with two sutures and then the original surgical procedure was completed as planned without incident. Coincidently, another incident involving an entrapped guidewire occurred on this same day with another similar Arrow catheter kit. In this case, the introducer needle entered the patient's radial artery, but partial advancement of the guidewire was met with resistance. When withdrawal of the guidewire was met with resistance, the entire apparatus was removed without further guidewire repositioning. This time the catheterization set was removed intact without difficulty.

There have been many accounts describing the risk of guidewire entrapment, uncoiling, and fragmentation, ${ }^{1}$ and some clinicians have questioned guidewire design $v s$ technique. ${ }^{2}$ With two consecutive incidences, we suspect a possible guidewire defect and not the technique employed, which was standard in both cases. In a previous report, a case similar to ours was described where the guidewire could not be retracted into the catheter and withdrawal of the whole unit was required. No uncoiling or guidewire complications occurred in this case. ${ }^{\mathrm{A}}$ In our first described case, we attempted further withdrawal and used a twisting motion on the guidewire before attempting to remove the whole guidewire, introducer needle, and catheter apparatus simultaneously. Our experience re-emphasizes the risks associated with withdrawing any guidewire back through an introducer needle. While it is common practice to retract

\footnotetext{
$\overline{\mathrm{A}}$ Manufacturer and User Facility Device Experience Database (MAUDE). Available at: http://www.patientsville.com/medical-device/ arterial-line-kit-quality.htm (accessed May 24, 2010).
} 


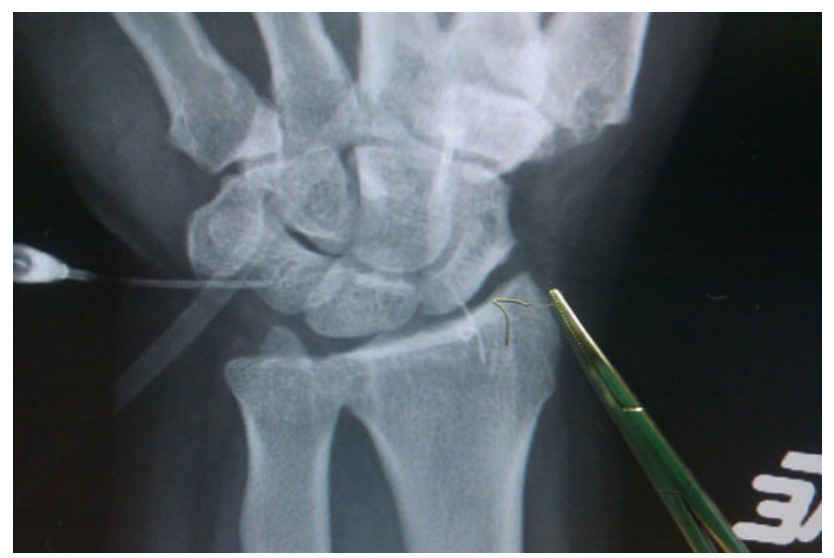

Figure Photo; $x$-ray showing guidewire retained in vivo and uncoiled retrieved guidewire in hemostat clamp. (Note uncoiled and kinked guidewire that likely contributed to its entrapment in subcutaneous tissues)

the guidewire into the catheter sheath when advancement into the vessel is unsuccessful, this approach must be performed with caution. We reiterate the importance of not attempting to withdraw the guidewire further and not using the twisting motion if any resistance is met. We also query the tensile strength and shearing threshold of the guidewire. ${ }^{3}$ The uncoiling was likely due to the guidewire being caught on the bevelled edge of the needle, and we have notified the manufacturer accordingly.

Competing interests None declared.

\section{References}

1. Yang FS, Ohta I, Chiang HJ, Lin JC, Shih SL, Ma YC. Nonsurgical retrieval of intravascular foreign body: experience of 12 cases. Eur J Radiol 1994; 18: 1-5.

2. Monaca E, Trojan S, Lynch J, Doehn M, Wappler F. Broken guide wire-a fault of design? Can J Anesth 2005; 52: 801-4.

3. Ceschinski H, Henkes H, Weinert HC, Weber W, Kuhne D, Monstadt $H$. Torquability of microcatheter guidewires: the resulting torsional moment. Biomed Mater Eng 2000; 10: 31-42. 